\title{
Behavioural and endocrine correlates to the aardwolf mating system
}

David Marneweck $^{\mathrm{a}}$, Elissa Z. Cameron ${ }^{\mathrm{b}, \mathrm{c}}$, Andre Ganswindt ${ }^{\mathrm{c}, \mathrm{d}}$, and Fredrik Dalerum $^{\mathrm{c}, \mathrm{e}^{*}}$

${ }^{a}$ Department of Zoology and Entomology, University of Pretoria, Private Bag X020, 0028

Pretoria, South Africa

${ }^{\mathrm{b}}$ School of Zoology, University of Tasmania, Hobart TAS 7001, Australia

${ }^{c}$ Mammal Research Institute, Department of Zoology and Entomology, University of Pretoria, Private Bag X020, 0028 Pretoria, South Africa

${ }^{\mathrm{d}}$ Endocrine Research Laboratory, Department of Anatomy and Physiology, University of Pretoria, Onderstepoort 0110, South Africa

${ }^{\mathrm{e}}$ Centre for Wildlife Management, Hatfield Experimental Farm, University of Pretoria, Private Bag X020, 0028 Pretoria, South Africa

\section{Correspondence}

Fredrik Dalerum

Mammal Research Institute, Department of Zoology and Entomology, University of Pretoria, Private Bag X020, 0028 Pretoria, South Africa

fredrik.dalerum@zoology.up.ac.za 


\begin{abstract}
It is now widely recognized that mating systems contain both social and genetic components, where social components describe patterns of social associations while genetic components reflect patterns of mating activities. In many species these two components do not coincide. If the level of sexual asymmetry differs between these two components, for instance in monogamous pairs with high levels of infidelity, each component may impose different selection pressures on behavioural and physiological characteristics. However, we have limited knowledge of how social and genetic components influence behaviour and physiology. The aardwolf (Proteles cristata) is a small insectivorous hyaenid, which has been described as socially monogamous but sexually promiscuous. In this study, we evaluated if aardwolf space use, scent marking, foraging behaviour and endocrine fluctuations relate to predictions from social monogamy or polygamous mating. Our results did not show sex differences in behaviour or physiology that would be consistent with predictions from polygamous mating, and we suggest that social mate associations may regulate the observed endocrine and behavioural parameters more than actual mating patterns in this species. Such an interpretation would suggest that the fitness effect of promiscuous mating may be low, since it appears to impose little selection pressure on mating related behaviour. We stress that it is then unclear how promiscuous mating is maintained in this socially monogamous species.
\end{abstract}

\title{
Keywords
}

mating system; carnivore; spatial behaviour; reproductive physiology; mammal 


\section{Introduction}

Mating systems are often categorized as four main classes; monogamy, polygyny, polyandry, and promiscuity (Clutton-Brock, 1989; Davies, 1991). The degree of sex differences in mating competition and mate fidelity typically lead to a gradient in sex differences in behaviours, where a greater inter-sexual asymmetry in behaviour is expected as sex differences in mating competition increase (e.g., Clutton-Brock et al., 1982). At one extreme of this gradient, socially monogamous pairs are characterized by inter-sexual symmetry in behaviour, whereas the other extreme is formed by mating systems with substantial mating competition in one sex, such as highly polygynous harem systems in mammals (e.g., Le Boeuf and Reiter, 1988).

Behavioural traits related to mating activities are proximately regulated by the individual's hormonal environment. For example, experimental administration of exogenous androgens during both the mating and non-mating seasons in monogamous male birds caused males to shift from monogamous to polygynous mating (Hegner and Wingfield, 1987; Silverin, 1980; Wingfield, 1984). However, different mating strategies may also result in contrasting hormone fluctuations, where particularly social rank may be associated with different levels of stress-related steroid hormones (Creel et al., 1996). As with behaviour, sex differences in hormonal fluctuations are expected to be related to mating competition. In particular, we would expect that lower individual variation within sexes is associated with low levels of competition, and subsequently that the difference in mating competition between males and females are related to within sex variation between individuals.

Mating activity is not necessarily constrained to long-term social relationships (Griffith et al., 2002). It is now widely recognised that mating systems have two components; a social component which describes how individuals socially relate to mating partners, and a genetic component which describes the genetic effects of actual mating events (Kappeler and van Schaik, 2002). Discrepancies between these two components in terms of the associations of males and females appear to be a rule rather than sporadic deviations (Birkhead and Møller, 1992). However, it is not yet clear to what extent the social versus the genetic components of mating systems influence behaviour and their hormonal characteristics.

The aardwolf (Proteles cristata) is an extreme resource specialist belonging to the family Hyenidae (De Vries et al., 2011; Koehler and Richardson, 1990; Matsebula et al., 2009). Aardwolves have been described as obligately monogamous socially (Koehler and Richardson, 1990; Richardson, 1985), as a result of the necessity for a high level of paternal care caused by the increased need for females to forage away from offspring during lactation (Richardson and Coetzee, 1988). However, aardwolves have been observed to engage in a high frequency of extrapair copulations (Richardson, 1987b; Sliwa, 1996), and Kotze et al. (2012) suggested that the temporal utilisation of dens corresponded more closely with predictions from polygamous mating than from social monogamy. Therefore, the aardwolf is an appealing candidate for evaluating how social versus genetic mating systems associate with sex differences in behaviour and endocrine fluctuations in a mammal.

The aim of this study was to test if sex-specific seasonal variation in behaviours and endocrine parameters relate to predictions from social monogamy in a population of wild aardwolves. In general, if social monogamy dictates behaviour and associated endocrine fluctuations, we would expect (i) symmetry between males and females in terms of their space use and behaviour due to similarities expected for a pair living, behaviourally monogamous species, (ii) symmetry between males and females in inter-individual variation in reproductive and stressrelated adrenocortical hormone concentrations, and (iii) that neither males nor females will exhibit increased adrenocortical hormone concentrations during the mating season. 


\section{Material and methods}

Study area

We conducted the study on Benfontein Nature Reserve, approximately $10 \mathrm{~km}$ southeast of Kimberley, Northern Cape Province, South Africa $\left(28.80^{\circ} \mathrm{S}, 24.77^{\circ} \mathrm{E}\right.$; Figure A.1). Benfontein covers 11,400 ha of semiarid terrain and lies within a transitional zone between dry Karoo, grassland and Kalahari thornveld (Schultze and McGee, 1978). The study area has a semiarid climate, with a dry season comprising March to August and a wet season September to February (Kotze et al. 2012). The reserve has hosted the majority of previous studies on aardwolf (De Vries et al., 2011; Ganswindt et al., 2012; Kotze et al., 2012; Richardson, 1985; Sliwa, 1996; Sliwa and Richardson, 1998).

\section{Study animals}

We immobilized seven wild aardwolves (four males and three females; Table 1) and fitted them with very high frequency radio collars (VHF; Sirtrack Ltd, Havelock North, New Zealand: weight $68.25 \mathrm{~g} \pm 8 \mathrm{~g}$, mean $\pm 1 \mathrm{sd}$ ). For this, we located aardwolves by driving around the reserve at night and scanning with a hand-held spotlight. Once an individual was located we followed it by a $4 \times 4$ vehicle from a distance of $>100 \mathrm{~m}$ until the animal became habituated to our presence. We remote injected aardwolves with a standard dose of $36.0 \mathrm{mg}$ ketamine hydrochloride and $0.6 \mathrm{mg}$ medetomidine hydrochloride using a $\mathrm{CO}_{2}$-powered remote injection system (Kotze et al. 2012). The darted animals took 5-10 minutes to become anaesthetized, and aardwolves were kept anaesthetized for 45-60 minutes. The medetomidine was subsequently reversed with $3.0 \mathrm{mg}$ of atipamezole hydrochloride. All individuals were fully mobile within 10 minutes after reversal, but we remained with the animals for approximately 30 minutes to ensure recovery. Animal handling procedures were approved by the Animal Use and Care Committee at University of Pretoria (EC031-07).

\section{Spatial and behavioural data collection}

Between March 2010 and July 2011 we relocated and observed radio-tagged aardwolves to record home range size and utilization as well as spatially explicit scent marking and foraging behaviour using a handheld PDA loaded with the software CyberTracker TM (http://www.cybertracker.org). We located each animal at its day time den, and once it had emerged we followed it for $84 \pm 50$ min (mean $\pm \mathrm{sd}$ ) to continuously record movements using a GPS unit. We recorded scent marking and foraging behaviours using a handheld PDA loaded with the software CyberTracker TM (http://www.cybertracker.org). In addition to record the coordinates of animal movements, we also stored a GPS coordinate for each logged behaviour. We defined scent marking as the action of an aardwolf straddling a grass stalk, rapidly squatting and wiping a smear of secretion onto the grass from the anal pouch (Richardson, 1985; Sliwa, 1996; Sliwa and Richardson, 1998). We defined foraging behaviour as the action of an aardwolf lowering its head to ground level and proceeding to lick traveling termites off the soil or mound surface into its mouth (Koehler and Richardson, 1990). In total, we recorded 269 spatial movement tracks and 157 behavioural sessions for the seven collared aardwolves (Table 1).

\section{Quantification of sex specific space use and behaviour}

We used 95\% Minimum Convex Polygons (MCPs: Mohr 1947) to estimate seasonal home range sizes for each animal. We based the MCP's on all pooled relocation data, including both data recorded during spatial data collection and opportunistic sightings recorded while following other study animals or moving around the study area for logistic reasons. We used MCP's to characterize home range size because they are relatively robust to possible temporal 
autocorrelation among data (Swihart and Slade, 1985). We calculated home range sizes using Hawth's Tools (http://www.spatialecology.com/htools).

We quantified home range utilization as densities of continuous movement tracks. We created line density isopleths which represent the density of linear features in the neighborhood of a pre-determined raster cell, measured as the length of lines per unit of area. We used a $20 \mathrm{~m} \mathrm{X}$ $20 \mathrm{~m}$ raster cell size as we typically were not more than $20 \mathrm{~m}$ from the animal being observed, and defined the search area as a circle around each raster cell. The radius of the search circle was calculated from the mean distance between 10,000 random points to the closest line segment within each aardwolf's annual home range, and ranged from $129.74 \mathrm{~m}$ to $496.28 \mathrm{~m}$ (mean $\pm \mathrm{sd}=$ $236.28 \pm 129.46)$.

We used a normalized Shannon spatial diversity index (H', Payne et al., 2005) to estimate the evenness of home range use in aardwolves. The index was calculated on the cell values of line densities:

$H^{\prime}=\frac{\sum_{i=1}^{K} P_{i} x \log \left(P_{i}\right)}{\log (R)}$

where $R$ is the number of pixels within each home range and $P_{i}$ is the relative abundance of the linear features within a raster cell (i.e. the length of linear features within the cell divided by the total length of linear features in all cells). An index value of 0 indicates complete unevenness in space use while a value of 1 indicates complete evenness. We did not conduct this analysis for each season due to low resolution in seasonal track data.

We calculated the number of scent markings and foraging bouts per 10 minutes for each behavioural session. We also quantified the proportion of time spent foraging for each session. We used two separate methods to quantify the spatial distribution of scent marking and foraging within individual home ranges for males and females. First, we intersected spatial coordinates of scent marking and foraging behaviours with the home range utilization estimate and extracted the utilization intensity (i.e. the density of movement tracks) for locations used for scent marking and foraging behaviours. Second, we calculated the distance between each scent mark and foraging bout to the nearest home range border as delineated from the 95\% MCP's to estimate where within the home ranges the different behaviours were conducted.

\section{Fecal sample collection, hormone metabolite extraction protocol and hormone assays}

We collected aardwolf feces while conducting spatial and behavioural observations on the habituated study animals. Generally, aardwolves defecated within 10-15 minutes after leaving their den, although they occasionally defecated at random times throughout their active period as well (Ganswindt et al., 2012). The intensity of sample collection varied both over time and between study animals (Table 1). At each observed defecation event, we collected 10-15g of faeces within 10 minutes of defecation after the study animal had moved away. We collected the fecal sample using rubber gloves and a thoroughly-mixed aliquot was stored in a glass vial. The glass vial containing the sample was placed on ice immediately and frozen at $-20^{\circ} \mathrm{C}$ directly after each behavioural observation period was concluded.

We lyophilised and pulverised the fecal samples and sifted them using a mesh strainer to remove fibrous material (Fieß, Heistermann and Hodges, 1999). Subsequently, approximately 0.2g of fecal powder was extracted with $3 \mathrm{ml}$ of $80 \%$ ethanol in water (Ganswindt et al., 2012). After vortexing for 15 minutes and following centrifugation at 3300rpm for 10 minutes, the supernatants were transferred into microcentrifuge tubes and stored at $-20^{\circ} \mathrm{C}$ until the hormone analysis. In addition, we determined the organic content of each sample according to the procedure described by Ganswindt et al. (2012). 
Resulting extracts were measured for immunoreactive faecal glucocorticoid metabolites (fGC) using an enzyme immunoassay (EIA) for cortisol (Palme and Möstl, 1997). This assay has been validated for determining changes in fGC concentrations in the aardwolf (Ganswindt et al. 2012). Sensitivity of the assay at $90 \%$ binding was $1.5 \mathrm{pg} /$ well. Intra-assay coefficients of variation (CV) were $9.5 \%$ and $11.0 \%$ for low and high quality controls, respectively. Inter-assay CV was $6.7 \%$ and $14.6 \%$ for low and high controls, respectively.

We quantified immunoreactive faecal androgen metabolites (fA) using an epiandrosterone EIA first described by Palme and Möstl (1994). Cross-reactivities of the epiandrosterone EIA antibody are described in Palme and Möstl (1994). Sensitivity of the assay at $90 \%$ binding was 8pg/well. Intra-assay CV ranged between $8.6 \%$ and $10.1 \%$ and Inter-assay CV between $13.5 \%$ and $14.6 \%$ for respective low and high quality controls. Since male mating activity is typically regulated by androgens in mammals, we evaluated the biological relevance of the fA assay by contrasting baseline, non-reproductively active, concentrations of fA in males to concentrations found during the dry season, which is when mating occurs. We calculated baseline fA values using an iterative process in which values that exceeded the mean plus 1.5 standard deviations (SD) were repeatedly excluded until no values exceeded the mean plus 1.5 SD (Brown et al., 1994). In males, fA concentrations during the dry season were elevated three and a half times above baseline (dry season $63.60 \mu \mathrm{g} / \mathrm{g}$ vs. baseline $18.60 \mu \mathrm{g} / \mathrm{g}$ ), which we regard as an adequate difference to infer that the assay provides physiologically relevant information.

We quantified immunoreactive faecal estrogen metabolites (fE) using an oestrone EIA first described by Palme and Möstl (1994). Cross-reactivities of the respective antibody are described in Palme and Möstl (1994). Sensitivity of the assay at $90 \%$ binding was $0.5 \mathrm{pg} / \mathrm{well}$. Intra-assay CV was 3.1\% and 5.6\% and inter-assay CV $11.7 \%$ and $13.7 \%$ for low and high controls, respectively. In seasonally breeding mammals, mating activity often correlates with overall higher oestrogen production in females. Therefore, we contrasted baseline oestrogen concentrations in females, calculated as described for androgens above, to those found during the mating season to evaluate the biological relevance of the $\mathrm{fE}$ assay. In females, $\mathrm{fE}$ concentrations were almost twice the baseline levels during the dry (mating) season $(112.40 \mathrm{ng} / \mathrm{g}$ vs. $59.00 \mathrm{ng} / \mathrm{g}$ ), suggesting that the assay provides physiologically relevant information.

We quantified immunoreactive faecal progestagen metabolites (fP) using a $5 \alpha$-pregnan-3ßol-20-one assay as first described by Szdzuy et al. (2006). Cross-reactivities of the respective antibody are given in Szdzuy et al. (2006). Sensitivity of the assay at 90\% binding was $3 \mathrm{pg} / \mathrm{well}$ and intra-assay CV was 3.6\% and $4.8 \%$ for low and high controls, respectively; while inter-assay CV was $8.5 \%$ and $15.7 \%$ for low and high controls, respectively. To evaluate the biological relevance of the FP EIA we contrasted baseline concentrations in females, calculated as described above, to those found during the gestation season for females with pregnancies confirmed by subsequent observations of offspring. In these females, fP concentrations were during the wet season 2.5 times higher than the baseline (wet season $33.60 \mu \mathrm{g} / \mathrm{g}$ vs. baseline $13.36 \mu \mathrm{g} / \mathrm{g}$ ).

For all assays, serial dilutions of fecal extracts yielded displacement curves which were parallel to the respective standard curve of the EIA. Data are presented as $\mu \mathrm{g} / \mathrm{g}$ dry extracted organic material for $\mathrm{fA}$ and $\mathrm{fP}$ concentrations while data are presented as ng/g dry extracted organic material for $\mathrm{fE}$ and fGC concentrations.

\section{Statistical analyses}

We used linear mixed-effects (LME) models to evaluate the effect of sex and season on home range size, scent marking rates, foraging rates, proportion of time spent foraging, utilization intensity of scent mark and foraging locations, and distance to border of scent mark and foraging locations. In all models we fitted sex, season and their two way interaction as fixed effect predictors. To account for heteroscedasticity we used a variance power function in the models on home range size, scent marking rates and foraging rates (Pinheiro and Bates, 2000) and an arcsine 
square root transformation in the model on proportion of time spent foraging. In the model on home range size we fitted animal identity as a random effect, whereas in the other models we fitted observation day grouped across each individual as the random effects structure. In all models except the one for home range size we fitted a spatial autocorrelation function to control for the spatial structure of our data points (Venables and Ripley, 1997). We evaluated fixed effects by conditional F-tests (Pinheiro and Bates 2000), and we used a Welch two sample t-test to test if there was a significant difference in the Shannon space use index between males and females. We highlight that our analyses of behaviour do not quantify total time budgets, but rather the relative rates of scent marking and foraging while each animal was active.

We similarly used LME's to evaluate the effect of season on concentrations of adrenocortical and reproductive hormone metabolites within each sex. We created separate models for each sex for fGC and fA, but we only created models on $\mathrm{fE}$ and $\mathrm{fP}$ for data from females. In each model, we used log transformed hormone metabolite concentrations as response variable and season as a fixed effect predictor. We controlled for non-independence within individuals as well as temporal pseudoreplication by fitting sample day grouped across each individual as a random effect structure. We evaluated fixed effects by conditional F-tests (Pinheiro and Bates, 2000), and we used variance ratio tests to evaluate seasonal differences in inter-individual variation on reproductive and adrenocortical hormones within each sex. Each test was conducted on individual means and we adjusted $\mathrm{p}$-values for multiple comparisons using the false discovery rate method (Benjamini and Hochberg, 1995).

We set statistical significance to 0.05 with all tests two tailed. We performed all statistical analyses with the software R, version 2.15.1 (http://www.R-project.org), using functions in the user contributed packages nlme (Pinheiro et al., 2012) and ramps (Venables and Ripley, 1997). We used ArcGIS version 9.3.2 with the spatial analyst tool to create the line density isopleths and extracted raster values for each logged behaviour using the Geospatial Modeling Environment (GME) program (www.spatialecology.com/gme/). Data represented in text and figures are mean \pm SE, unless otherwise stated.

\section{Results}

\section{Home range size and utilization}

Males had larger home ranges than females $(F=8.28$, d.f. $=1,5, p=0.03)$, but there was no difference between the two seasons $(F=3.76$, d.f. $=1,5, p=0.11)$ nor an interaction of sex and season on home range size $(F=0.18$, d.f. $=1,5, p=0.69$; Figure 1A). Males used their home ranges more evenly than females $(t=4.13$, d.f. $=5, p=0.01$; Figure $1 \mathrm{~B})$, although both males and females had Shannon index values close to completely even use.

\section{Patterns of scent marking and foraging behaviour}

Males scent marked more than females $(F=7.84$, d.f. $=1,5, p=0.04)$, and both males and females scent marked more in the wet than in the dry season $(F=10.97$, d.f. $=1,145, p<0.01$; Figure $2 \mathrm{~A})$. There was no interaction of sex and season on scent mark rates $(F=1.25$, d.f. $=1,145, p=0.26)$. Females foraged more than males $(F=8.89$, d.f. $=1,5, p=0.03$; Figure 2B). However, foraging rates did not differ between seasons $(F=2.87$, d.f. $=1,145, p=0.09)$, nor was there an interaction of sex and season $(F=0.0001$, d.f. $=1,5, p=0.99)$. Neither $\operatorname{sex}(F=6.04$, d.f. $=1,5, p=0.06)$, season $(F=3.26$, d.f. $=1,145, p=0.07)$ nor the interaction of $\operatorname{sex}$ and $\operatorname{season}(F=0.06$, d.f. $=$ $1,145, p=0.80$ ) affected proportion of time spent foraging (Figure 2C).

Neither $\operatorname{sex}(F=0.74$, d.f. $=1,5, p=0.43)$, season $(F=0.06$, d.f. $=1,3709, p=0.80)$ nor the interaction of sex and season $(F=0.16$, d.f. $=1,3709, p=0.69)$ affected either the utilization rate of scent mark locations (Figure $3 \mathrm{~A}$ ) or the distance of scent mark locations to nearest home range border (sex: $F=5.19$, d.f. $=1,5, p=0.07$; season: $F=0.25$, d.f. $=1,3709, p=0.61$; sex x season: $F$ $=0.28$, d.f. $=1,3709, p=0.60$; Figure 3B). Similarly, neither $\operatorname{sex}(F=2.41$, d.f. $=1,5, p=0.18)$, 
season $(F=0.52$, d.f. $=1,3003, p=0.47)$ nor the interaction of sex and season $(F=0.01$, d.f. $=$ $1,3003, p=0.93$ ) had affected the utilization intensity of foraging locations (Figure 3C). However, there was an interaction effect of sex and season on the distance of foraging locations to nearest home range border $(F=1272.93$, d.f. $=1,3003, p<0.01)$, where females foraged further from the home range borders in the wet season compared to the dry season while there were little seasonal differences for males (Figure 3D).

\section{Endocrine fluctuations}

There were no differences between dry and wet seasons in fGC concentrations for neither females $(F=0.57$, d.f. $=1,83, p=0.45)$ nor males $(F=0.49$, d.f. $=1,75, p=0.49$; Figure 4A $)$. There was no difference between dry and wet season in fA concentrations for females $(F=0.05$, d.f. $=1,83, p$ $=0.82)$, but males had higher fA concentrations during the dry than during the wet season $(F=$ 13.64, d.f. $=1,75, p<0.01$; Figure 4B). For females, there were no differences between dry and wet season for $\mathrm{fE}(F=0.56$, d.f. $=1,61, p=0.46)$ or $\mathrm{fP}(F=1.18$, d.f. $=1,83, p=0.28)$ concentrations (Figure 4C,D).

Dry and wet seasons did not differ in inter-individual variation of fGC concentrations for females $\left(F=0.25\right.$, d.f. $\left.=2,2, p_{a d j}=0.47\right)$, but there was a trend for wet season to have higher interindividual variation than the dry season in males $\left(F=0.01\right.$, d.f. $\left.=2,3, p_{a d j}=0.07\right)$. Contrarily, in females there was a higher inter-individual variation of fA concentrations in the dry than in the wet season $\left(F=2466.19\right.$, d.f. $\left.=2,2, p_{a d j}<0.01\right)$, but there were no seasonal difference in males $(F=$ 5.04 , d.f. $\left.=2,3, p_{a d j}=0.33\right)$. In females, there were no seasonal differences in inter-individual variation of $\mathrm{fE}$ concentrations $\left(F=2.66\right.$, d.f. $\left.=2,2, p_{a d j}=0.55\right)$, but there were a greater variation of $\mathrm{fP}$ concentrations in the dry than in the wet season $\left(F=1145.43\right.$, d.f. $\left.=2,2, p_{a d j}<0.01\right)$.

\section{Discussion}

Our results suggested that there were sex differences in both home range size and space use. However, these differences did not seem to have been directly related to optimization of male mating opportunities. If male aardwolves were trying to continuously maximise extra mating opportunities we would expect their home ranges to be orders of magnitude larger than females to include as many females as possible within their home range (Emlen and Oring, 1977). This was not the case. In addition, in contradiction to earlier observations on this species (Sliwa and Richardson, 1998), males utilized their range more evenly than females, suggesting that their activity was not concentrated to the periphery of the home range where extra-pair mating partners would be located. Androgens have been positively related to roaming behaviour (Chandler et al., 1994), and we suggest that the larger home range size and more even movement patterns in males compared to females could have been androgen driven, and represent potentially non-adaptive behaviours indirectly related to mating strategies through their hormonal regulation.

We similarly found sex differences in aardwolf scent marking behaviour. However, we again suggest that these results were not directly related to mating competition, because the required increase in sex-related difference in the dry (which contain the mating period) compared to the wet season was lacking. Scent marking behaviour functions as a way of advertising ownership of a territory (Gosling and Roberts, 2001). However, if male aardwolves scent mark as a way of mate guarding we would expect scent marking rates to increase during the dry season, as well as being more concentrated along the periphery of their ranges to ward off potential rivals (Gorman, 1990; Sliwa and Richardson, 1998). Our data instead showed that both male and female aardwolves scent marked more during the wet season and that neither sex concentrated their scent marks at the border of their ranges. The wet season is a period of intense offspring dependency at natal dens (Koehler and Richardson, 1990). We therefore suggest that scent marking may function 
as a way of protecting the territory from intruders to secure enough food resources to successfully raise offspring. The observation of higher scent marking rates in males compared to females may be attributed to sex differences in behaviour within a monogamous pair where males could be more involved in the protection of resources.

The lack of differences between sexes and seasons in the time spent foraging suggests no cost of reproductive activities in terms of foraging time. Therefore, we suggest that the observed sex differences in the frequency of foraging bouts reflect non-mating related differences in male and female foraging behaviour. For females, we further found a seasonal variation in the spatial distribution of foraging locations where they foraged further from home range borders in the wet compared to the dry season. This may be caused by a central tendency towards maternal dens when offspring are present (Joshi et al., 1999; Kotze et al., 2012). An alternative, not mutually exclusive explanation could be that the observed seasonal variation in foraging locations was caused by decreased food availability around foraging dens after dry season. The lack of seasonal variation in the spatial location of foraging sites for males suggests a less pronounced fidelity to natal dens than females.

Similarly to the behavioural data, physiological data generally appear to better fit predictions based on social monogamy. Our results showed no seasonal differences in fGC concentrations in either males or females, that the seasonal difference in individual variation of male fGC concentrations contradicted predictions based on polygynuous mating, and that females experienced no seasonal differences in individual variation of estrogens. However, we note that mating may only occur during a few weeks in this species (Sliwa 1996), which may mute endocrine fluctuations averaged across whole seasons. Intra-sexual competition is strongly correlated with aggressive interactions which typically result in social rank relationships (Creel, 2005). In species exhibiting such relationships dominant and subordinate individuals typically differ in their circulating glucocorticoid concentrations, although the direction of these differences is related to the stability of the rank relationships (Creel, 2005). Our fGC results may therefore suggest a lack of distinct rank relationships among wild aardwolves. Contrarily, however, females exhibited higher individual variation of androgens during the mating season, which may suggest that females, but not males, experience some mating competition, supportive of previous suggestions of promiscuous mating. However, since female aardwolves are not group living they have limited access to directly influence neighboring females' reproduction. It is therefore not clear what the function might be of a potentially androgen mediated increase in female aggression during the mating season.

This is the first study to present reproductive hormone data for wild aardwolves. Our results support previous observations of the aardwolf as a strictly seasonal breeder (Koehler and Richardson, 1990; Marneweck et al., 2012; Richardson 1987; Sliwa, 1996) with seasonal fluctuations in fA concentrations in males and two observed litters during the wet season. However, although progestagen production also varied between seasons in females, fE concentrations were not consistently elevated during the dry season, which contains the mating activity. This observation is consistent with that of many other mammals (Bronson and Heideman, 1994). Since we do not know if females are mono- or polyoestrous, it could be difficult to detect a rise during the mating season if cyclic patterns were reflected by a peak in a single fecal sample (e.g., Brown, 2006). However, we found indications of pro-oestrous in wild aardwolves where fE and $\mathrm{fP}$ concentrations increased during the mating season. Furthermore, we could not confirm mating activities in all our study animals, thus introducing the possibility that mating status may have influenced variation in behaviour and physiology also within sexes.

Although recent data suggested some behavioural support for promiscuity in wild aardwolves (Kotze et al., 2012), this study indicates that space use, scent marking and foraging behaviour as well as endocrine fluctuations may be more strongly linked to social monogamy. These results suggest that social mating associations may regulate the observed endocrine and 
behavioural parameters more than actual mating patterns. Such an interpretation would suggest that the fitness effect of promiscuous mating is low despite the observed occurrence of EPCs, since promiscuity did not seem to impose a major selection pressure on behaviour and physiology. While the cost of promiscuous mating for females may only be related to male willingness to provide paternal care, it is less clear how males would benefit from promiscuous mating while still exhibiting social monogamy and paternal care, since it potentially could prompt them to invest in other males' offspring. However, we stress that further research is needed to directly quantify promiscuity using genetic markers, and subsequently to assess the fitness consequences of promiscuous mating tactics for males and females.

Finally, we highlight that our results were based on a low sample size which prevented our conclusions to be based on statistically robust analyses. Similar problems are inherent with many carnivore field studies, and caused by logistical difficulties related to the low densities, tendencies to move over large areas, and often cryptic, nocturnal and solitary behaviour exhibited by most carnivores (Bekoff et al., 1984). Despite our low sample size, we used high-resolution data on individually recognized wild aardwolves to quantify sex-specific behaviour and endocrine physiology. Although mating related influences on behaviour and physiology may only be apparent during short time periods, and hence potentially missed with our sampling protocols, we still argue that this study provides important information regarding behavioral and physiological associations to mating tactics in this cryptic species.

\section{Acknowledgements}

We are grateful to the De Beers Ecology Division and the Diamond Route for permission to work on Benfontein Game Reserve, and to the staff and managers at Benfontein for logistic support. The study was financially supported by an NRF focal area grant (EZC), NRF incentive funds (FD), an NRF SARCHi chair in mammal behavioural ecology and physiology awarded to Prof. Nigel Bennett and a research fellowship from University of Pretoria (FD). We thank the numerous field assistants that aided with field data collection, in particular Robynne Kotze, Rick Beishuizen and Wouter Brekelman as well as Stefanie Ganswindt for expert help with laboratory techniques. Dr Joseph Van Heerden kindly assisted with acquiring appropriate permits for animal handling.

\section{References}

Anestis, A., Pörtner, H.O., Karagiannis, D., Angelidis, P., Staikou, A., Michaelidis, B., 2010. Response of Mytilus galloprovincialis (L.) to increasing seawater temperature and to marteliosis: metabolic and physiological parameters. Comp. Biochem. Physiol. 56, 57-66.

Bekoff, M., Daniels, T.J., Gittleman, J.L., 1984. Life history patterns and the comparative social ecology of carnivores. Ann. Rev. Ecol. Syst. 15, 191-232

Benjamini, Y., Hochberg, Y., 1995. Controlling the false discovery rate: a practical and powerful approach to multiple testing. J. Roy. Stat. Soc. B 57, 289-300.

Birkhead, T.R., Møller, A.P., 1992. Sperm Competition in birds: evolutionary causes and consequences. Academic Pressm, London.

Bronson, F.H., Heideman, P.D., 1994. Seasonal regulation of reproduction in mammals, in: Knobil, E., Neill, J.D., Greenwald, G.S., Markert, C.L., Pfaff, D.W. (eds.), The Physiology of Reproduction: Volume 1. Raven Press, New York, pp 541-584.

Brown, J.L., 2006. Comparative endocrinology of domestic and nondomestic felids. Theriogenol. 66, 25-36.

Chandler, C.R., Ketterson, E.D., Nolan, V., Ziegenfus, C., 1994. Effects of testosterone on spatial activity in free ranging male dark-eyed juncos, Junco hyemalis. Anim. Behav. 47, 1445-1455

Clutton-Brock, T.H., 1989. Mammalian mating systems. Proc. Roy. Soc. B 236, 339-372. 
Clutton-Brock, T.H., Guinness, F.E., Albon, S.D., 1982. Red deer: Behaviour and ecology of two sexes. Edinburgh University Press, Edinburgh.

Creel, S., 2005. Dominance, aggression, and glucocorticoid levels in social carnivores. J. Mamm. $86,255-264$.

Creel, S., Creel, N.M., Monfort, S.L., 1996. Social stress and dominance. Nature 379, 212.

Davies, N.B., 1991. Mating systems, in: Krebs, J.R., Davies, N.B. (eds.), Behavioural Ecology: An evolutionary approach, 3rd Edition. Blackwell Scientific Publications, Oxford, pp. 263-294.

De Vries, J.L., Pirk, C.W.W., Bateman, P.W., Cameron, E.Z., Dalerum, F., 2011. Extension of the diet of an extreme foraging specialist, the aardwolf (Proteles cristata). Afr. Zool. 16, 194-196.

Emlen, S.T., Oring, L.W., 1977. Ecology, sexual selection and the evolution of mating systems. Science 197, 215-223.

Fieß, M., Heistermann, M., Hodges, J.K., 1999. Patterns of urinary and fecal steroid excretion during the ovarian cycle and pregnancy in the African elephant (Loxodonta africana). Gen. Comp. Endocrinol. 115, 76-89.

Ganswindt, A., Muilwijk, C., Engelkes, M., Muenscher, S., Bertschinger, H., Paris, M., Palme, R., Cameron, E.Z., Bennett, N.C., Dalerum, F. 2012. Validation of non-invasive monitoring of adrenocortical endocrine activity in ground feeding aardwolves (Proteles cristata); exemplifying the influence of consumption of inorganic material for fecal steroid analysis. Physiol. Biochem. Zool. 85, 194-199.

Gorman, M.L., 1990. Scent marking strategies in mammals. Rev. Sui. Zool. 97, 3-29.

Gosling, L.M., Roberts, S.C., 2001. Scent-marking by male mammals: Cheat-proof signals to competitors and mates. Adv. St. Behav. 30, 169-217.

Griffith, S.C., Owens, I.P.F., Thuman, K.A., 2002. Extra pair paternity in birds: a review of interspecific variation and adaptive function. Mol. Ecol. 1, 2195-2212.

Hegner, R.E., Wingfield, J.C., 1987. Effects of experimental manipulation of testosterone levels on parental investment and breeding success in male house sparrows. Auk 104, 462-469.

Joshi, A.R., Smith, J.L.D., Garshelis, D.L., 1999. Sociobiology of the myrmecophagous sloth bear in Nepal. Can. J. Zool. 77, 1690-1704.

Kappeler, P.M., van Schaik, C.P., 2002. Evolution of primate social systems. Int. J. Primatol. 23, 707-740.

Koehler, C.E., Richardson, P.R.K., 1990. Proteles cristatus. Mamm. Spec. 363, 1-6.

Kotze, R., Bennett, N., Cameron, E., De Vries, L., Marneweck, D., Pirk, C. and Dalerum, F., 2012. Temporal patterns of den use suggest polygamous mating patterns in the socially monogamous aardwolf. Anim. Behav. 84, 1573-1578.

Le Boef, B.J., Reiter, J., 1988. Lifetime reproductive success in northern elephant seals, in: Clutton-Brock, T.H. (ed), Reproductive success: studies of individual variation in contrasting breeding systems. University of Chicago Press, Chicago, pp. 344-363.

Matsebula, S.N., Monadjem, A., Roques, K.G., Garcelon, D.K., 2009. The diet of the aardwolf, Proteles cristatus at Malolotja Nature Reserve, western Swaziland. Afr. J. Ecol. 47, 448-451.

Mohr, C.O., 1947. Table of equivalent populations of North American small mammals. Am. Midl. Nat. 37, 223-249.

Palme, R., Möstl, E., 1994. Biotin-streptavidin enzyme immunoassay for the determination of oestrogens and androgens in boar faeces, in: Proceedings of the $5^{\text {th }}$ Symposium on the Analysis of Steroids (1993-05-04). Akademiai Kiado, Szombathely, pp. 111-117.

Palme, R., Möstl, E., 1997. Measurement of cortisol metabolites in faeces of sheep as a parameter of cortisol concentration in blood. Z. Säuget. 62, 192-197.

Payne, L.X., Schindler, D.E., Parrish, J.K., Temple, S.A., 2005. Quantifying spatial pattern with evenness indices. Ecol. Appl. 15, 507-520. 
Pinheiro, J.C., Bates, D.M., 2000. Mixed effect models in S and S-plus. Springer-Verlag, New York.

Pinheiro, J.C., Bates, D.M., DebRoy, S., Sarkar, D., 2012. Nlme: linear and nonlinear mixed effects models. R package version 3.1-104.

Richardson, P.R.K., 1985. The social behaviour and ecology of the aardwolf, Proteles cristatus, (Sparrman, 1783) in relation to its food resources. Ph.D. thesis, University of Oxford, UK.

Richardson, P.R.K., 1987. Aardwolf mating system: overt cuckoldry in an apparently monogamous mammal. S. Afr. J. Sci. 83, 405-410.

Richardson, P.R.K., Coetzee, M., 1988. Mate desertion in response to female promiscuity in the socially monogamous aardwolf Proteles cristatus. S. Afr. J. Zool. 23, 306-308.

Schulze, R.E. and McGee, O.S., 1978. Climatic indices and classifications in relation to the biogeography of southern Africa, in: Werger, M.J.A., Junk, W. (Eds.), Biogeography and Ecology of South Africa. Springer Verlaag, Hague, pp. 19-52.

Silverin, B., 1980. Effects of long-acting testosterone treatment on free-living pied flycatchers, Ficedula hypoleuca, during the breeding period. Anim. Behav. 28, 906-912.

Sliwa, A., 1996. A functional analysis of scent marking and mating behaviour in the aardwolf, Proteles cristatus (Sparrman, 1783). Ph.D. thesis, University of Pretoria, RSA.

Sliwa, A., Richardson, P.R.K., 1998. Responses of aardwolves, Proteles cristatus, Sparrman 1783, to translocated scent marks. Anim. Behav. 56, 137-146.

Swihart, R.K. and Slade, N.A., 1985. Testing for independence of observations in animal movements. Ecology 66, 1176-1184.

Szdzuy, K., Dehnhard, M., Strauss, G., Eulenberger, K., Hofer, H., 2006. Behavioural and endocrinological parameters of female African and Asian elephants. Int. Zoo. Yearb. 2006 40, 41-50.

Venables, W.N., Ripley, B.D., 1997. Modern Applied Statistics with S-plus, 2nd Edition. New York: Springer-Verlag.

Wingfield, J.C., 1984. Androgens and mating systems: testosterone-induced polygyny in normally monogamous birds. Auk 101, 665-671. 
A)

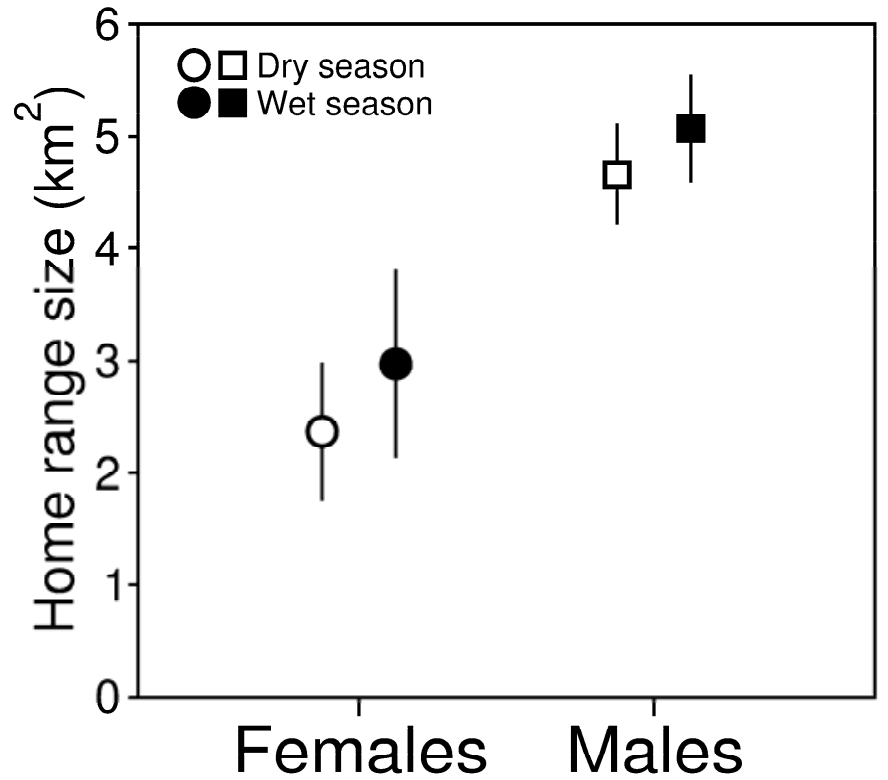

B)

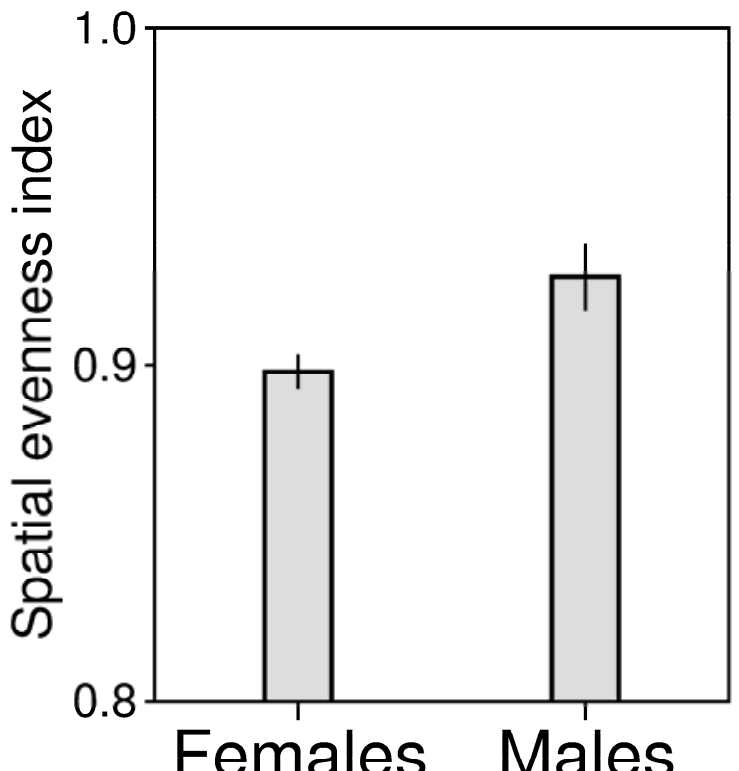

Fig. 1. Home range sizes (A) and spatial evenness indices $(B)$ for female $(n=3)$ and male $(n=4)$ aardwolves. Home range sizes were delineated using 95\% minimum convex polygons and the evenness of spatial utilization was calculated with a normalized Shannon spatial diversity index, where a value close to 1 indicates even use of space. Data represent mean $\pm \mathrm{SE}$ of individual means. 
A)

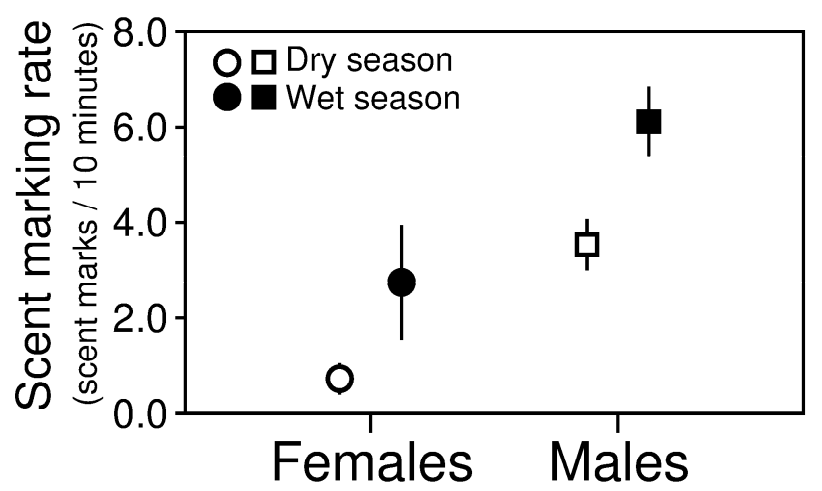

B)

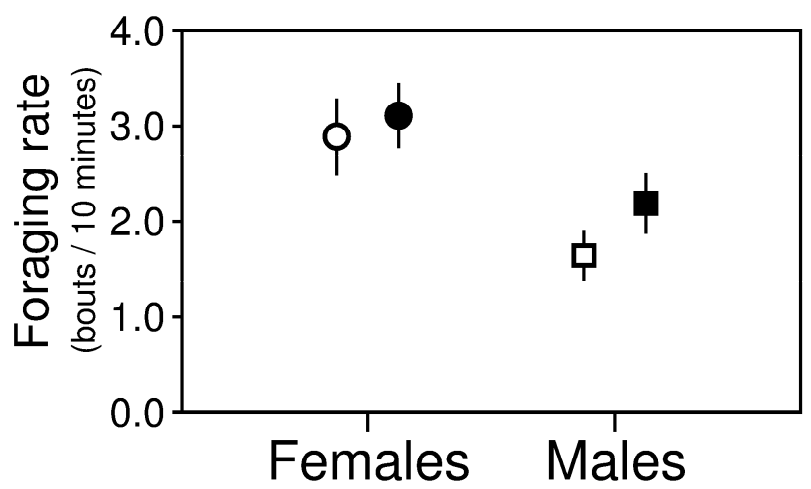

C)

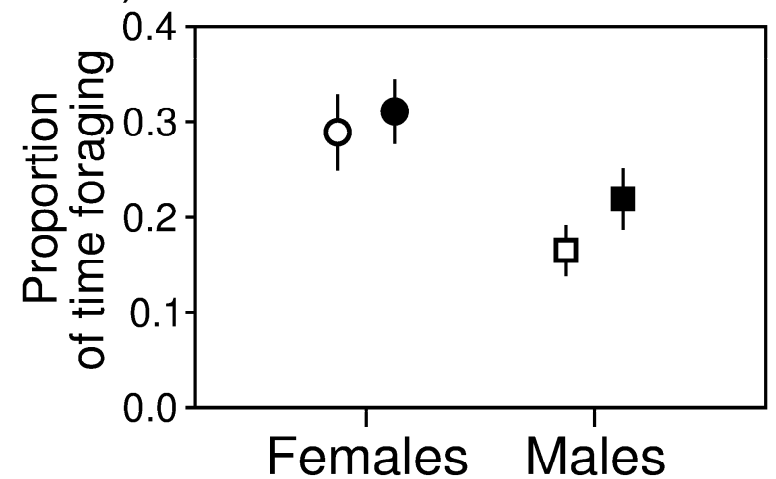

Fig. 2. Scent marking rates (A), foraging rates (B) and proportion of time spent foraging (c) for female $(n=3)$ and male $(n=4)$ aardwolves during dry and wet seasons. Data represent mean $\pm \mathrm{SE}$ of individual means. 
A)

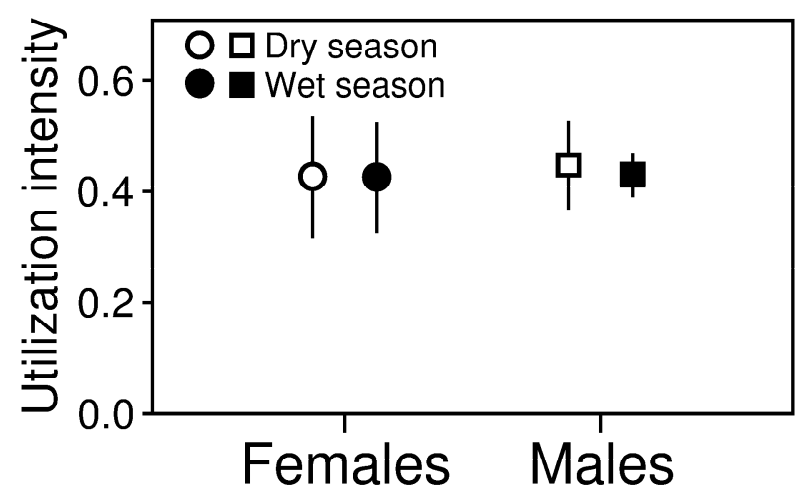

C)

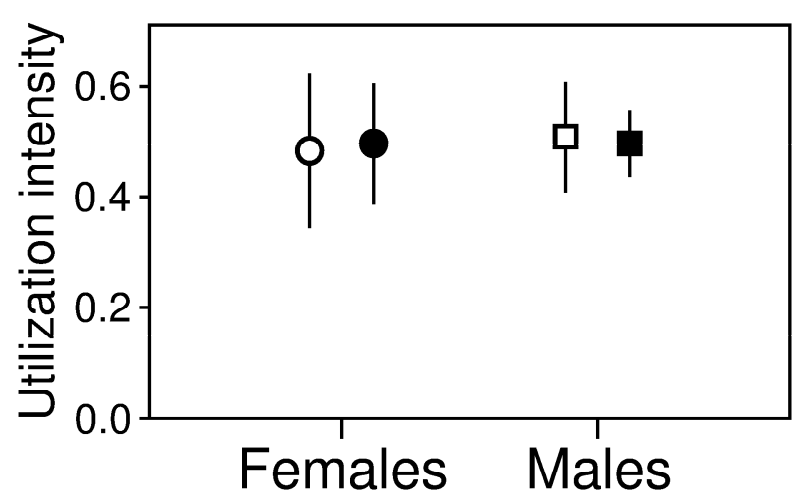

B)

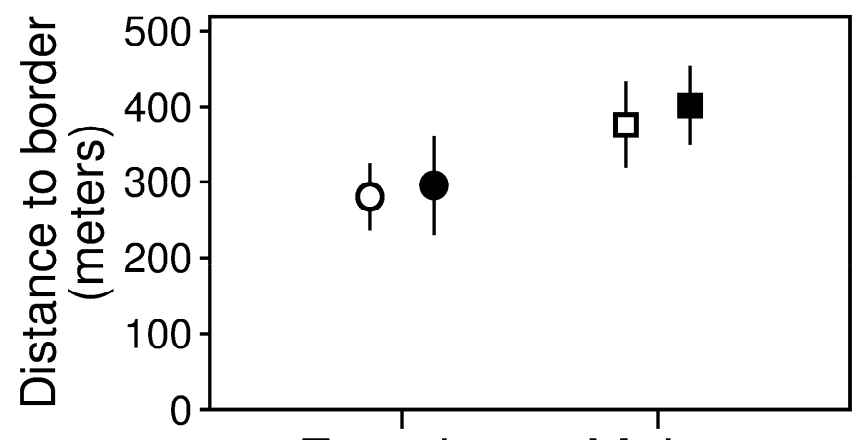

D)

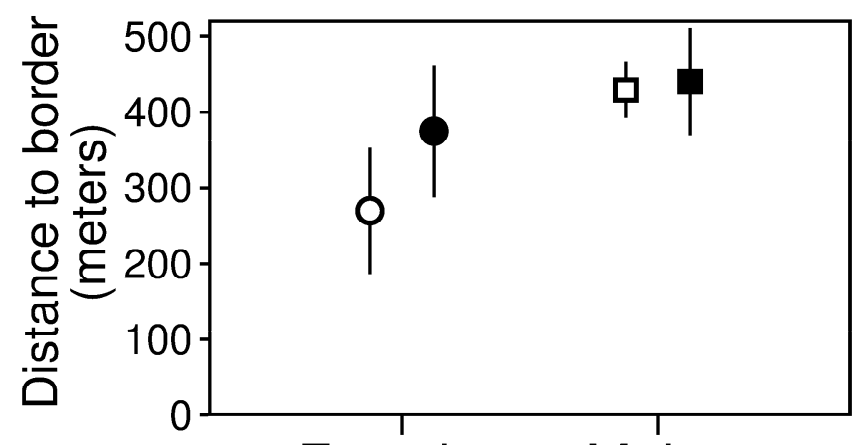

Females Males

Fig. 3. Spatial utilization intensity (expressed as metres of movement tracks per square metre of area) and distance to nearest home range border of locations used for scent marking (A, B) and for foraging $(C, D)$. Utilization intensities were determined from the intersection of spatial coordinates of scent marking and foraging with home range utilization estimates. Home range borders were delineated from $95 \%$ minimum convex polygons. Data represent mean $\pm \mathrm{SE}$ of individual means. 
A)

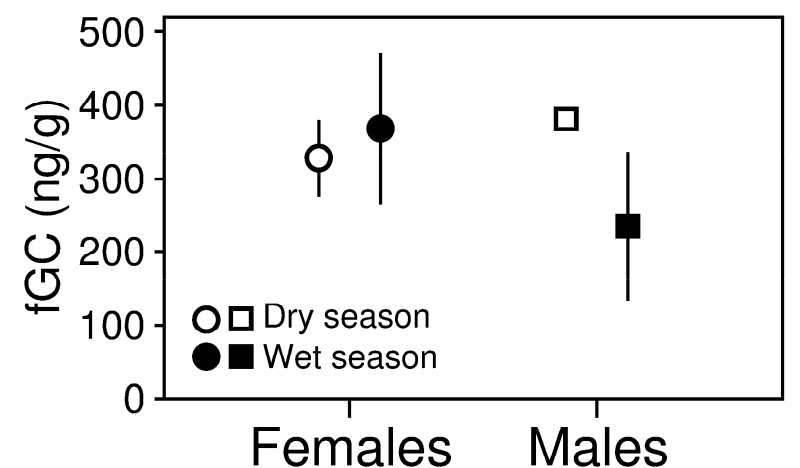

C)

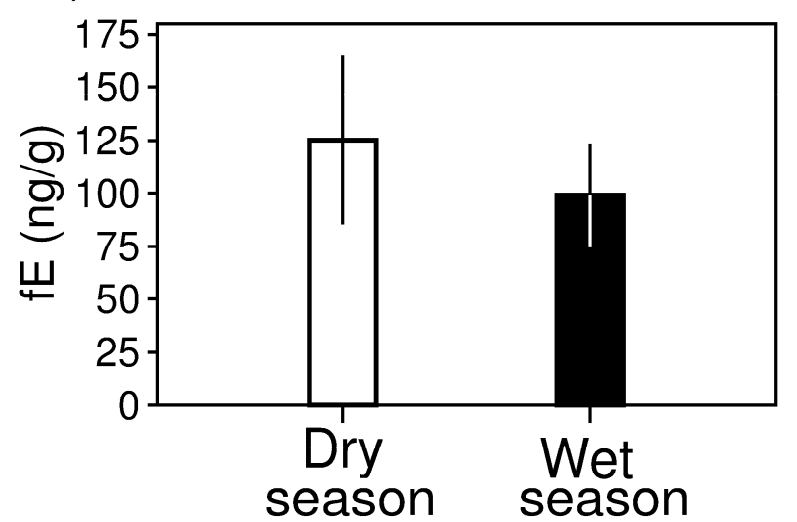

B)

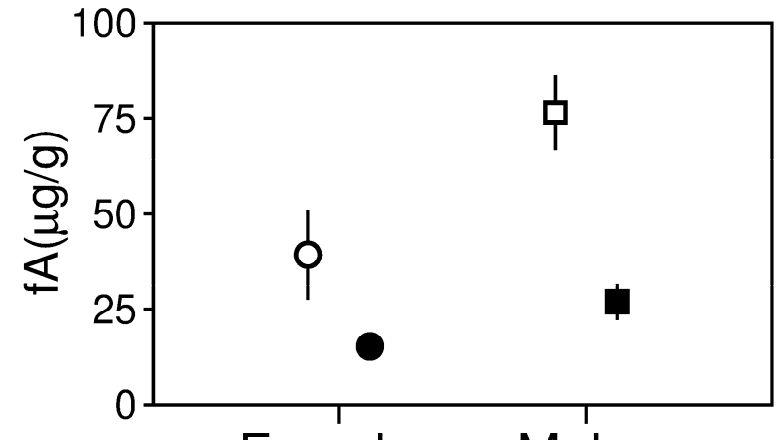

D)

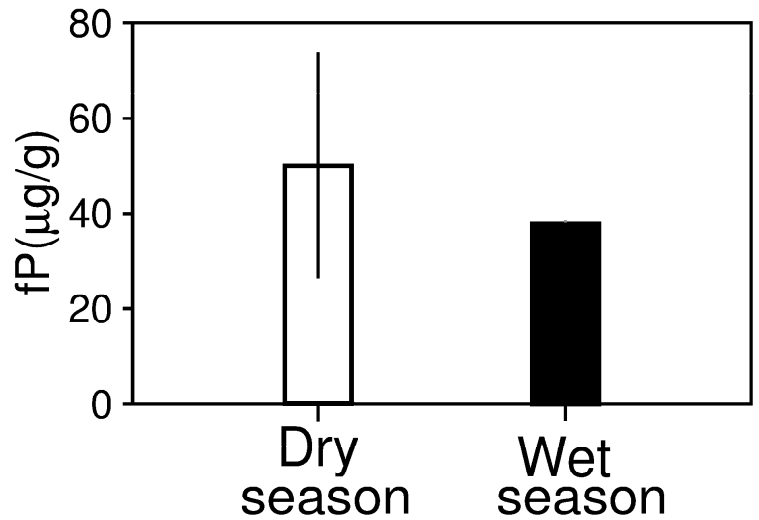

Fig. 4. Concentrations of fGC (A) and fA (B) in males and female aardwolves and concentrations of $\mathrm{fE}(\mathrm{C})$ and $\mathrm{fP}(\mathrm{D})$ in females during dry and wet seasons. Data represent mean $\pm \mathrm{SE}$ of individual means, and are expressed as $\mu \mathrm{g} / \mathrm{g}$ (fA and $\mathrm{fP}$ ) or $\mathrm{ng} / \mathrm{g}$ ( $\mathrm{fGC}$ and $\mathrm{fE}$ ) dry organic material. 


\section{Table 1}

Behavioural observations and endocrine fecal samples for seven aardwolves on Benfontein Nature Reserve. Number of spatial tracks, sessions where behavioural data was recorded and analyzed fecal samples for each of the seven aardwolves on Benfontein Nature Reserve during the wet and the dry season. Behavioural sessions ranged between 2-316 ( $84 \pm 50$, mean \pm sd) minutes. Figures within brackets are the number of tracks or behavioural observation sessions.

\begin{tabular}{|c|c|c|c|c|c|c|c|c|c|c|c|c|c|}
\hline \multirow[b]{2}{*}{ ID } & \multirow[b]{2}{*}{ Sex } & \multirow[b]{2}{*}{$\begin{array}{l}\text { Period } \\
\text { followed }\end{array}$} & \multicolumn{3}{|c|}{ Time (min) of tracks } & \multicolumn{3}{|c|}{ Time (min) of behavioural sessions } & \multicolumn{3}{|c|}{ No. fecal samples } & \multirow[b]{2}{*}{$\begin{array}{l}\text { Mating } \\
\text { partner }\end{array}$} & \multirow[b]{2}{*}{$\begin{array}{l}\text { No. } \\
\text { litters }\end{array}$} \\
\hline & & & Wet season & Dry season & Total & $\begin{array}{c}\text { Wet } \\
\text { season }\end{array}$ & Dry season & Total & $\begin{array}{c}\text { Wet } \\
\text { season }\end{array}$ & $\begin{array}{c}\text { Dry } \\
\text { season }\end{array}$ & Total & & \\
\hline BWF08006 & Fem & $\begin{array}{l}\text { May } 2010 \text { - } \\
\text { Dec } 2010\end{array}$ & $1991(27)$ & $606(14)$ & $2597(41)$ & $\begin{array}{l}785(11) \\
65 \pm 39^{\mathrm{a}}\end{array}$ & $\begin{array}{l}475(8) \\
59 \pm 16\end{array}$ & $1260(19)$ & 26 & 3 & 29 & $M 8^{b}$ & 2 \\
\hline BWF09009 & Fem & $\begin{array}{l}\text { May } 2010 \text { - } \\
\text { July } 2011\end{array}$ & $1861(24)$ & $3256(32)$ & $5117(56)$ & $\begin{array}{c}1036(12) \\
86 \pm 42\end{array}$ & $\begin{array}{c}2505(23) \\
109 \pm 83\end{array}$ & $3541(35)$ & 40 & 8 & 48 & $\mathrm{M}^{\mathrm{c}}$ & 2 \\
\hline BWF10015 & Fem & $\begin{array}{l}\text { July } 2010 \text { - } \\
\text { April } 2011\end{array}$ & $1560(13)$ & $396(6)$ & $1956(19)$ & $\begin{array}{l}649(8) \\
81 \pm 38\end{array}$ & $\begin{array}{l}283(4) \\
71 \pm 35\end{array}$ & $932(12)$ & 8 & 2 & 10 & None $^{\mathrm{e}}$ & None $e^{e}$ \\
\hline BWM09008 & Male & $\begin{array}{l}\text { May } 2010- \\
\text { April } 2011\end{array}$ & $1756(20)$ & $735(13)$ & $2491(33)$ & $\begin{array}{l}333(4) \\
83 \pm 60\end{array}$ & $\begin{array}{c}641(10) \\
64 \pm 22\end{array}$ & $974(14)$ & 24 & 0 & 24 & $\mathrm{~F} 6^{\mathrm{b}}, \mathrm{F} 9^{\mathrm{c}}$ & 1 \\
\hline BWM10012 & Male & $\begin{array}{l}\text { May } 2010 \text { - } \\
\text { June } 2011\end{array}$ & $2026(22)$ & $1236(19)$ & $3262(41)$ & $\begin{array}{l}669(8) \\
95 \pm 46\end{array}$ & $\begin{array}{c}1023(15) \\
68 \pm 33\end{array}$ & $1692(23)$ & 2 & 4 & 6 & $\mathrm{Unk}^{\mathrm{cdf}}$ & None $^{e}$ \\
\hline BWM10014 & Male & $\begin{array}{l}\text { May } 2010 \text { - } \\
\text { July } 2011\end{array}$ & $986(10)$ & $3604(36)$ & $4591(46)$ & $\begin{array}{c}931(9) \\
103 \pm 40\end{array}$ & $\begin{array}{c}2733(30) \\
91 \pm 41\end{array}$ & 3664 (39) & 7 & 8 & 15 & None $^{e}$ & 1 \\
\hline & & Total & $12301(135)$ & $10800(134)$ & & $4837(58)$ & $8206(99)$ & & 140 & 27 & & & \\
\hline
\end{tabular}

${ }^{\mathrm{a}}$ Mean $\pm \mathrm{sd} ;{ }^{\mathrm{b}} 2009$ Mating season; ${ }^{\mathrm{c}} 2010$ Mating season; ${ }^{\mathrm{d}} 2011$ Mating season; ${ }^{\mathrm{e}}$ No mating activity or litters was observed; ${ }^{\mathrm{f}}$ Was observed with an unmarked mating partner 


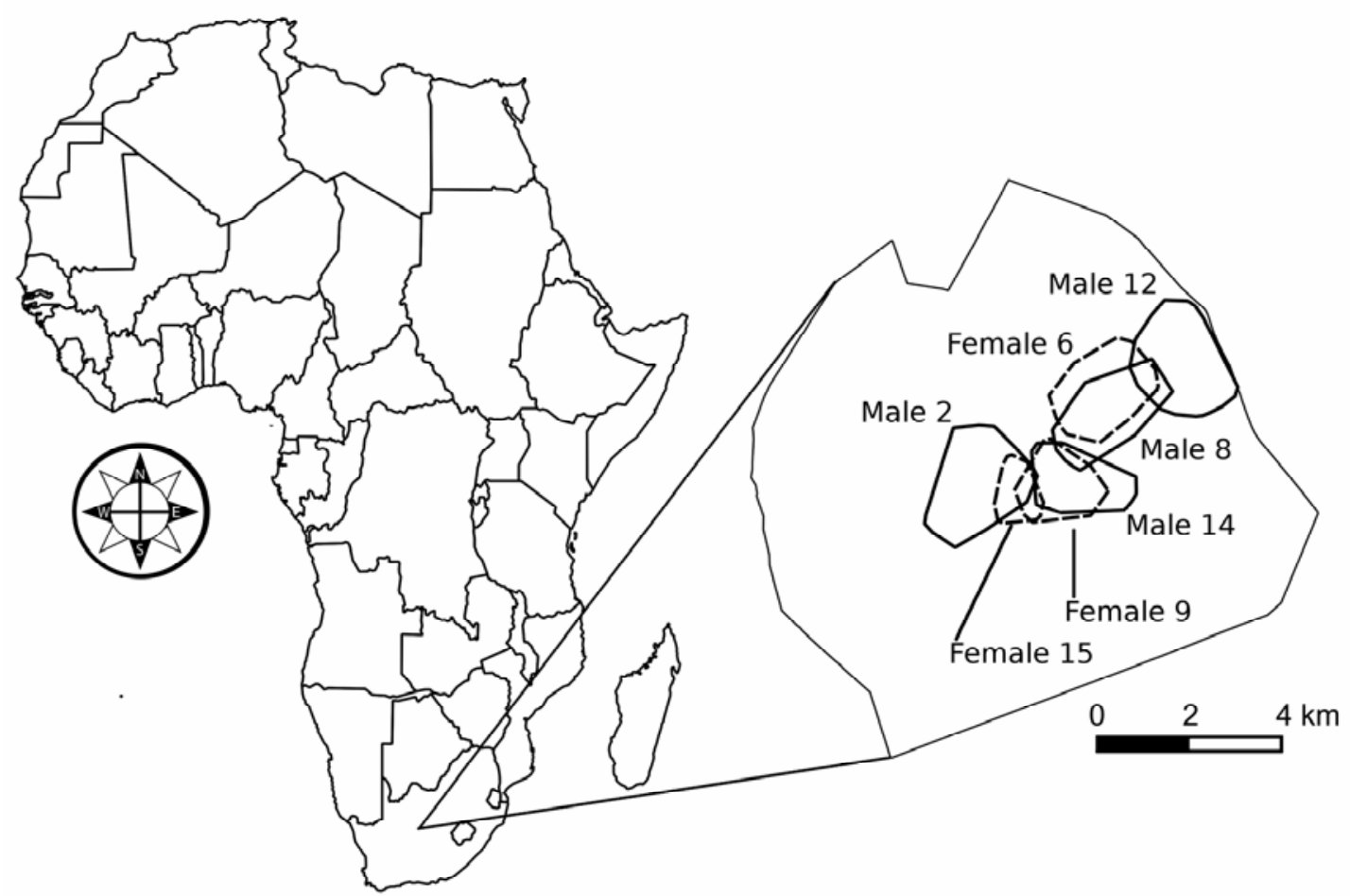

Fig. A.1. Geographic location of the study area Benfontein Nature Reserve, situated approximately $10 \mathrm{~km}$ south-east of Kimberley, Northern Cape Province, South Africa, as well as the home ranges of the habituated study animals estimated from $95 \%$ Minimum Convex Polygons (MCPs). 